\title{
Mechanical Properties of Magnetron Sputtered Free Standing Mg-Ag Alloy Films
}

\author{
Lea K. Jessen, Christiane Zamponi and Eckhard Quandt* \\ Chair of Inorganic Functional Materials, Institute for Materials Science, Faculty of Engineering, Kiel University, Kiel, Germany
}

Magnesium based alloys gained great interest for medical biodegradable applications. Limitations arise from high corrosion rates and mechanical properties of the $\mathrm{Mg}$ based alloys. In recent work it was shown that the corrosion rate of a precipitate free Mg$6 \mathrm{Ag}$ thin film can be reduced by a factor of three compared to pure sputtered Mg. As Mg-6Ag combines the very promising corrosion results with a potential therapeutically use of Ag ions, the investigation of their mechanical properties is needed for a full characterization of Mg-Ag alloys as biodegradable material. In this work the Ag content was varied from 2 to $10 \mathrm{wt} \%$. The investigated thin film samples were dog-bone shaped samples with a thickness of $20 \mu \mathrm{m}$. The samples were fabricated by a combination of UV lithography, sacrificial layer technique and magnetron sputtering. The mechanical

\section{OPEN ACCESS}

Edited by:

Hajo Dieringa,

Helmholtz Centre for Materials and Coastal Research (HZG), Germany

Reviewed by:

Jindrich Musil,

University of West Bohemia, Czechia

Thomas Ebel,

Helmholtz Centre for Materials and Coastal Research (HZG), Germany

*Correspondence: Eckhard Quandt eq@tf.uni-kiel.de

Specialty section:

This article was submitted to

Structural Materials,

a section of the journal

Frontiers in Materials

Received: 24 May 2019 Accepted: 10 September 2019 Published: 25 September 2019

Citation: Jessen LK, Zamponi C and Quandt E (2019) Mechanical Properties of Magnetron Sputtered Free Standing

Mg-Ag Alloy Films.

Front. Mater. 6:236.

doi: 10.3389/fmats.2019.00236 properties were determined using uniaxial tensile test. Compared to pure Mg samples fabricated by the same processing route the yield strength is approximately doubled for Ag containing samples. For films with a Ag concentration up to $8 \mathrm{wt} \%$ the elongation at fracture reaches a value of $\sim 7 \%$. Further increase of the Ag concentration leads to lower elongation at fracture. Thus, especially due to the low corrosion rate, Mg-6Ag shows the optimum of all investigated alloys, with a yield strength of $\sim 310 \mathrm{MPa}$ and an elongation at fracture of $\sim 6 \%$.

Keywords: magnetron sputtered thin films, Mg-Ag alloys, biodegradable, mechanical properties, microstructure

\section{INTRODUCTION}

The research in the field of biodegradable materials is increased over the last decade (Zheng et al., 2014). Magnesium (Mg) and Mg based alloys are attractive candidates for biodegradable metallic implants (Li et al., 2004; Song, 2007). A limitation of these materials is a high corrosion rate. This limits the functional stability and thus the intended medical purpose of the implant (Hermawan et al., 2010; Zheng et al., 2014). Mg based alloys are used to tailor the corrosion rate as well as the mechanical properties. Commonly used alloying elements are for example $\mathrm{Zn}, \mathrm{Ca}$, or rare earths such as Y, Gd, Nd (Song, 2007; Witte et al., 2008; Hermawan, 2012; Zheng et al., 2014).

In the case of bulk materials an additional solution heat treatment with quenching (T4 heat treatment) (ASM International, 1992a) is needed because otherwise precipitates are formed. The temperatures and times differ depending on the alloy composition and sample size.

For the sputtered thin films, no additional heat treatment is necessary because magnetron sputtering is a non-equilibrium process which allows the fabrication of metastable supersaturated materials in certain compositional ranges exceeding the stable conditions (ASM International, 1992a; Li et al., 2004; Song, 2007; Witte et al., 2008; Hermawan et al., 2010; Hermawan, 2012; Schlüter et al., 2014; Zheng et al., 2014). Additionally, this leads to a high defect density in the 
fabricated films. The special microstructure of sputtered films compared to bulk material has an influence on the mechanical properties.

Mechanical tests on sputtered thin films were performed earlier on Mg-rare earth alloys (Schlüter et al., 2014). These alloys are known for their good mechanical properties, respectively, its high strength (Gao et al., 2009a,b; Hort et al., 2010). The mechanical and corrosion behavior of as deposited magnetron sputtered binary and ternary Mg-rare earth alloys were investigated. $\mathrm{Mg}-5 \mathrm{Y}$ and $\mathrm{Mg}-5 \mathrm{Gd}$ showed an elongation at fracture of $\sim 20 \%$ and a yield strength of $\sim 240 \mathrm{MPa}$. Even higher yield strength could be obtained for Mg-20Y with $\sim 400$ $\mathrm{MPa}$ however the elongation at fracture was reduced to $\sim 6 \%$ (Schlüter et al., 2014). Mg-4Y-3Gd and Mg-4Y-3Nd was tested as well. The yield strength of the materials was in the range of 220-260 MPa and the elongation at fracture varied between 0 and 20\% dependent on the sputter pressure (Schluter et al., 2011; Schlüter et al., 2013). The sputtered Mg-rare earth alloys showed promising mechanical properties. However, there is research necessary to find biocompatible alloys, which show even a lower corrosion rate compared to Mg-rare earth alloys.

The alloys of the Mg-Ag system are interesting for the use as an implant material because in this system, the biodegradable properties of $\mathrm{Mg}$ are combined with the antibacterial properties of Ag (Lansdown, 2002; Mijnendonckx et al., 2013; Tie et al., 2013; Liu et al., 2017). The Mg-Ag films could be for example used to avoid inflammations caused by the implantation. It was shown for bulk materials that it is possible to achieve a single phase material with an additional T4 solution heat treatment up to $6 \mathrm{wt} \% \mathrm{Ag}$ (Tie et al., 2013; Liu et al., 2017; Maier et al., 2018). A solubility of low concentration of Ag (< 15 wt\% Ag@ $745 \mathrm{~K}$ ) in $\mathrm{Mg}$ is theoretically achievable according to the $\mathrm{Mg}-\mathrm{Ag}$ phase diagram (ASM International, 1992b). The Mg-Ag bulk alloys with up to $6 \mathrm{wt} \%$ showed a decrease in the corrosion rate compared to $\mathrm{Mg}$ and $\mathrm{Mg}-\mathrm{Ag}$ alloys without any solution heat treatment (Maier et al., 2015, 2018; Liu et al., 2017). The lowest corrosion rate for in vitro test was obtained for $\mathrm{Mg}-2 \mathrm{Ag}$ measured in Dulbecco's modified Eagle's medium (DMEM) (Tie et al., 2013). At higher concentrations of Ag, precipitates were formed which led to an increased corrosion rate (Liu et al., 2017). The multi-phase microstructure was formed in the bulk material if no solution heat treatment was applied. Magnetron sputtered $\mathrm{Mg}$-Ag films showed even lower corrosion rates compared to the bulk (Jessen et al., 2019). This is most probably the result of the special microstructure which is obtained by sputtering as well as the small grain diameter smaller than $1 \mu \mathrm{m}$. It was shown that the crystallographic orientation within the sample plays a role as well as the grain size (Liu et al., 2008; Jiang et al., 2017). For the sputtered films it was possible to achieve a precipitate free material up to $6 \mathrm{wt} \%$ Ag without an additional heat treatment. When the concentration was increased to $8 \mathrm{wt} \% \mathrm{Ag}$ the formation of precipitates started but no influence on the corrosion rate was found. In the case of $\mathrm{Mg}-10 \mathrm{Ag}$ more and larger precipitates were detected which led to the formation of a galvanic cell and results in an increased corrosion rate. The lowest corrosion rate with $0.04 \pm 0.01 \mathrm{~mm} /$ year was achieved for $\mathrm{Mg}$-6 Ag which is by a factor of approximately three lower than Mg (Jessen et al., 2019).
Another important criterium for biodegradable metallic implants are their mechanical properties namely the strength as well as the elongation at fracture. The Young's modulus of Mg alloys is about 45 GPa (ASM International, 1992a), which is compared to other metals e.g., Fe with a Young's modulus of $200 \mathrm{GPa}$, close to that of bone (3-20 GPa). For this reason, Mg is a welcome material for orthopedic applications, because the likelihood of stress shielding is minimized (Staiger et al., 2006; Hermawan, 2012). For bulk materials, the mechanical properties of Mg-Ag alloys were investigated on cylindrical specimens and wires. The test of the cylindrical samples of Mg-6Ag showed an increase of tensile strength by a factor two compared to $\mathrm{Mg}$ (Tie et al., 2014). Furthermore, wires of Mg-6Ag were tested, they showed an ultimate strength of $\sim 350 \mathrm{MPa}$ and an elongation at fracture of $\sim 5 \%$. A solution heat treatment reduced the strength to $\sim 240 \mathrm{MPa}$ but increased the elongation at fracture by a factor of two to $\sim 10 \%$ (Maier et al., 2015, 2018).

For a detailed material analysis, a characterization of the mechanical properties is important. This is the reason why in this study the mechanical properties of as deposited sputtered $\mathrm{Mg}-\mathrm{Ag}$ alloys free standing films showing very promising corrosion rates are investigated. Only the as deposited samples are investigated, because any additional heat treatment will lead to larger grains or precipitates, which will increase the corrosion rate again (Ralston et al., 2010). For the mechanical testing uniaxial tensile test on $20 \mu \mathrm{m}$ thick samples were performed. Due to the fact of having free standing sputtered films it is possible to perform tensile tests to determine the mechanical properties. If the films were used as a coating, indentation measurements are needed to determine the hardness and Young's modulus which allows the estimation of crack formation (Musil, 2012, 2015). The influence of varying Ag content between 2 and $10 \mathrm{wt} \%$ on the mechanical properties will be determined. The obtained results will be compared to pure $\mathrm{Mg}$ free standing films fabricated by the same processing route.

\section{EXPERIMENTAL}

\section{Fabrication}

A combination of UV lithography and magnetron sputtering was used to fabricate the $20 \mu \mathrm{m}$ thick free standing film samples. For tensile test dog-bone shaped samples were used, see Figure 1. The overall length of the dog-bone shaped sample is $14 \mathrm{~mm}$. The strut has a length of $7 \mathrm{~mm}$, a parallel length of $5.5 \mathrm{~mm}$ and a width of $0.5 \mathrm{~mm}$. A mask aligner MA6-8 (Süss MicroTec, Germany) was used for UV lithography. The sputtering was performed in a cluster magnetron sputtering machine Von Ardenne CS730S (VON ARDENNE, Germany). For the fabrication process silicon ( $\mathrm{Si}$ ) wafers with a diameter of $100 \mathrm{~mm}$ were used as a substrate material. First the Si substrate was structured by UV lithography, then aluminum ( $\mathrm{Al})$, which served as a hard mask for the following Bosch process (Laermer and Schilp, 1996), was deposited on the structured wafer. The deep etching process is necessary to achieve the free standing dog-bone shaped samples. Aluminum nitride (AlN) as a sacrificial layer is deposited on the dry etched substrate, followed by the sputtering of the $\mathrm{Mg}$ - $\mathrm{Ag}$ alloy. Potassium hydroxide $(\mathrm{KOH})(20 \%)$ was used to etch selectively the sacrificial AlN layer to achieve the free standing 


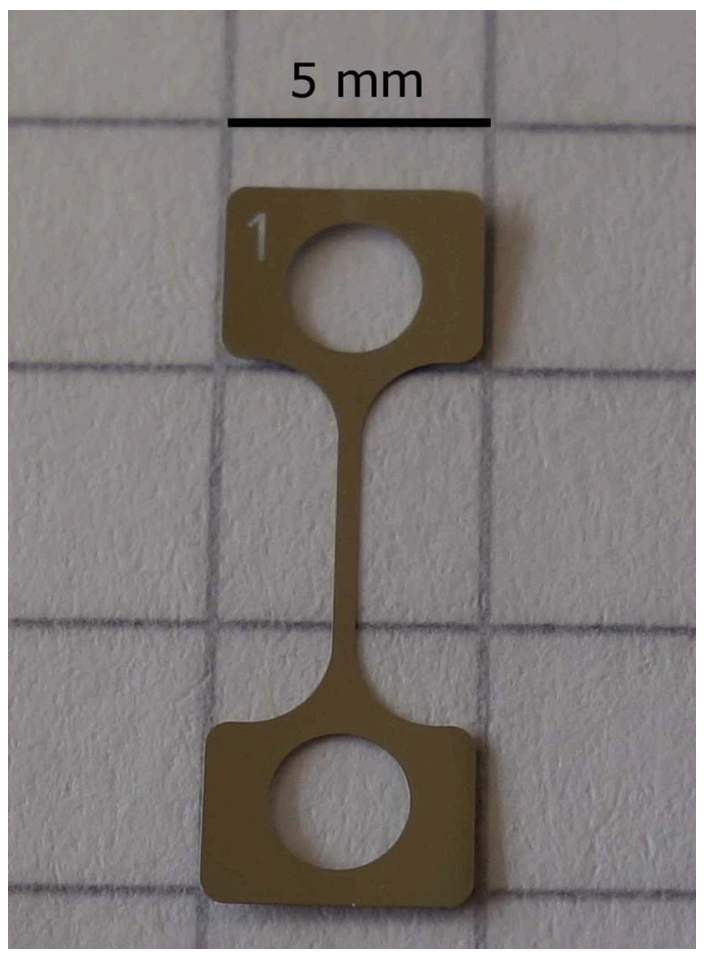

FIGURE 1 | Image of a dog-bone shaped sample.

dog-bone shaped samples. Further details on the fabrication process can be found in (Haffner et al., 2015).

The following targets were used for the different materials: pure $\mathrm{Mg}$, pre alloyed targets of: $\mathrm{Mg}-2 \mathrm{Ag}, \mathrm{Mg}-6 \mathrm{Ag}, \mathrm{Mg}-8 \mathrm{Ag}$, Mg-10Ag (FHR, Germany) the compositions of the alloys are given in $\mathrm{wt} \%$. The achieved composition of the sputtered films is equal to the target composition (Jessen et al., 2019). The sputtering power was set to $200 \mathrm{~W}$ for $\mathrm{Mg}$ (200 mm diameter) and to $50 \mathrm{~W}$ for all the $\mathrm{Mg}$ - $\mathrm{Ag}$ alloy targets (each $100 \mathrm{~mm}$ diameter). The argon (Ar) gas flow was set to $25 \mathrm{sccm}$ for all sputter depositions. The sputtering pressures of the different materials were varied between $1.8 \cdot 10^{-3}$ mbar and $3.0 \cdot 10^{-3}$ mbar in order to minimize the film stress of the different materials. The substrate temperature was measured by temperature stripes which indicated a range between $71^{\circ} \mathrm{C}$ and $77^{\circ} \mathrm{C}$ for all depositions. Table 1 summarizes the sputter parameters.

\section{Analysis of Microstructure}

To evaluate the microstructures of the different as deposited samples, cross sections were prepared by focused ion beam (FIB). Using a Helios NanoLab 600 (FEI, Germany) associated with a scanning transmission electron microscopy (STEM) detector. A transmission electron microscope (TEM) [F30 G2STwin (Tecnai, FEI, Germany)] was employed to analyze the microstructure of the prepared cross sections in more detail.

\section{Mechanical Properties}

To determine the mechanical properties uniaxial tensile tests were performed using the above described dog-bone shaped samples. A tensile test machine of the type BETA 5-5/6 $\times 10$ (Messphysik, Austria), with a special sample holder for thin samples was used. A strain rate of $0.4 \% / \mathrm{min}$ was applied and as fracture criterion, a force reduction of $60 \%$ relative to the maximum applied force was used. For each type, at least eight samples were measured to assess the statistic reliability. From these measurements the average values and standard deviation of the yield strength $\left(\mathrm{R}_{\mathrm{p} 0.2}\right)$ and elongation at fracture were determined.

\section{Analysis of Fracture}

After tensile testing the fractured surface and the surrounding area was investigated using a scanning electron microscope (SEM) (Zeiss Ultra Plus, Germany). X-ray diffraction (XRD) (SmartLab $9 \mathrm{~kW}$, Rigaku, Japan) was used to identify the orientation of the columnar grains in a deformed state and a non-deformed state. Therefore, rocking curves were measured at different positions on the sample after tensile test. One measurement was performed on the head of the dog-bone; this is the reference measurement in a non-deformed area of the dogbone (head). Another measurement was done at the strut near the head of the dog-bone, this is an area with only slight deformation [strut (head)]. The last measurement was performed next to the fractured surface in a high deformed area (strut (fracture). All measurements were done using $\mathrm{Cu} \mathrm{K}_{\alpha}$ radiation. The rocking curve was performed in a $\omega$ range of $\pm 8^{\circ}$ around the (0002) peak $\left(\omega=17.23^{\circ}\right)$ with a step size of $0.02^{\circ}$ and scan speed of $8^{\circ} / \mathrm{min}$.

\section{RESULTS}

\section{Analysis of Microstructure}

An overview of a cross section of a sputtered film ( $~ 10 \mu \mathrm{m}$ thick) is shown in Figure 2a. The typical columnar growth of sputtered $\mathrm{Mg}$ based alloys is observable. The growth direction of the film is indicated as well as the direction of tensile force during the tensile test which is perpendicular to the growth direction. On the left side smaller grains are visible, where the film growth started. The grain diameter close to the surface of the sputtered samples is smaller than $1 \mu \mathrm{m}$. The preferential orientation of the film was determined by XRD. Due to the lowest surface energy of the (0001) plane of the hexagonal close packed structure the growth direction in [0001] is favored. (Thompson, 1990; ASM International, 1999; Gottstein, 2004; Mahieu, 2006; Jessen et al., 2019). Figure $\mathbf{2 b}$ shows a cross section of $\mathbf{M g}$ at higher magnification. Figure $2 \mathrm{c}$ shows a cross section of $\mathrm{Mg}-6 \mathrm{Ag}$ at higher magnification that exhibits a special microstructure which resembles feather-like, so in the following it is referred to as feather-like microstructure. This microstructure will form due to agglomeration of $\mathrm{Ag}$ richer areas within a $\mathrm{Mg}$ based matrix. In the case of Mg-10Ag (also higher magnification) binary MgAg precipitates are formed, see Figure 2d (Jessen et al., 2019). The Mg-Ag precipitates could be not clearly assigned to the possible intermetallic phases like $\mathrm{Mg}_{54} \mathrm{Ag}_{17}, \mathrm{Mg}_{7} \mathrm{Ag}_{3}$, or $\mathrm{Mg}_{3} \mathrm{Ag}$ (Tie et al., 2014; Liu et al., 2015a,b; Ren et al., 2018). 
TABLE 1 | Sputter parameters of the different materials.

\begin{tabular}{|c|c|c|c|c|c|c|}
\hline Material & $\begin{array}{l}\text { Sputtering pressure } \\
\left(10^{-3} \mathrm{mbar}\right)\end{array}$ & $\begin{array}{l}\text { Gas flow (Ar } \\
\text { sccm) }\end{array}$ & Power (W) & $\begin{array}{c}\text { Target } \\
\text { diameter } \\
(\mathrm{mm})\end{array}$ & $\begin{array}{c}\text { Substrate } \\
\text { deposition } \\
\text { temperature }\left({ }^{\circ} \mathrm{C}\right)\end{array}$ & $\begin{array}{l}\text { Deposition } \\
\text { rate }(\mathrm{nm} / \mathrm{s})\end{array}$ \\
\hline $\mathrm{Mg}$ & 2.1 & 25 & 200 & 200 & $71-77$ & 1.85 \\
\hline $\mathrm{Mg}-2 \mathrm{Ag}$ & 2.3 & 25 & 50 & 100 & $71-77$ & 2.55 \\
\hline $\mathrm{Mg}-6 \mathrm{Ag}$ & 3.0 & 25 & 50 & 100 & $71-77$ & 2.58 \\
\hline $\mathrm{Mg}-8 \mathrm{Ag}$ & 2.6 & 25 & 50 & 100 & $71-77$ & 2.52 \\
\hline $\mathrm{Mg}-10 \mathrm{Ag}$ & 1.8 & 25 & 50 & 100 & $71-77$ & 2.27 \\
\hline
\end{tabular}

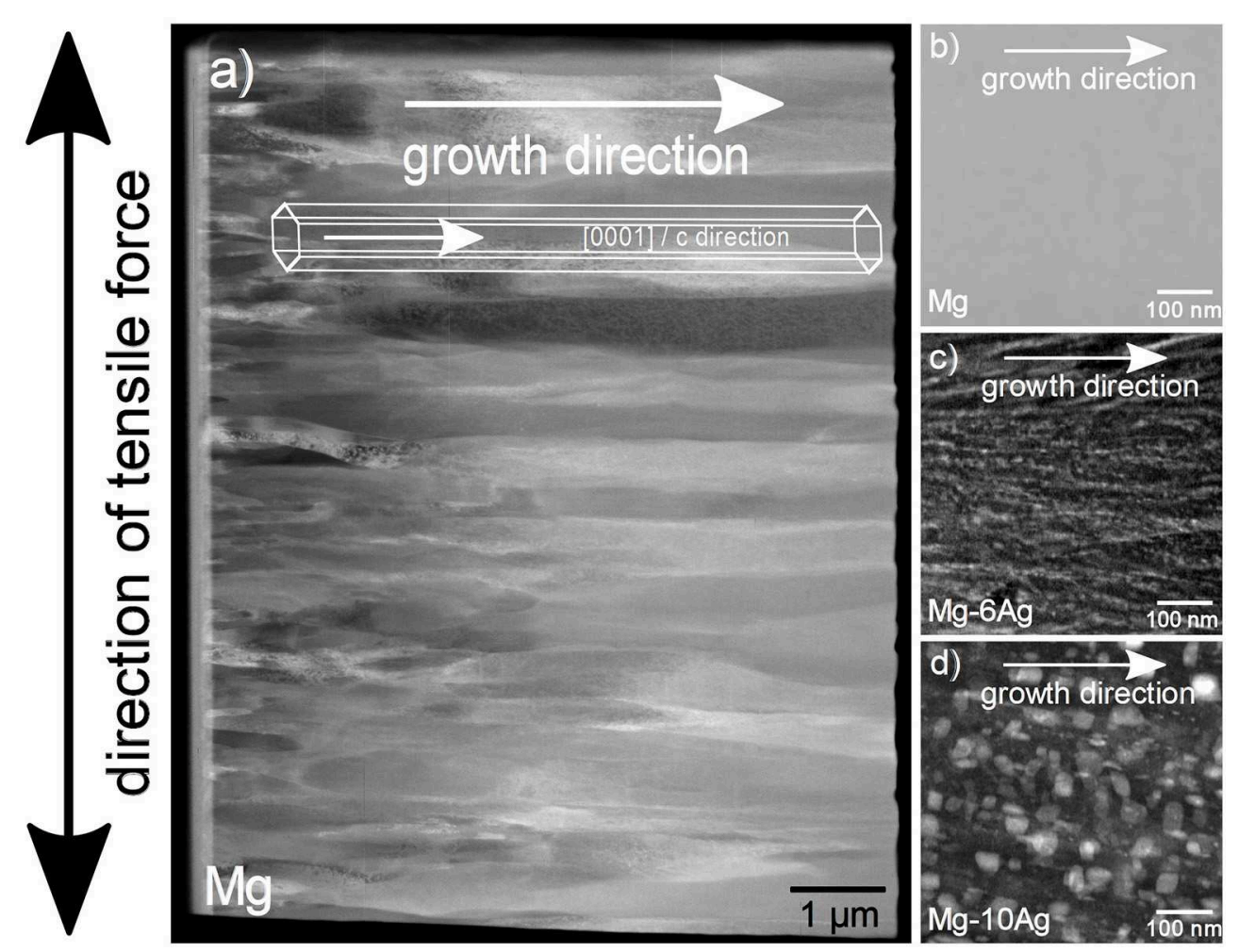

FIGURE 2 | STEM images of cross sections (a) Overview image of magnetron sputtered Mg based material, showing a columnar growth, furthermore is the growth direction of the film indicated which is perpendicular to the direction of applied tensile force. (b) Enlarged image of the microstructure of Mg. (c) Enlarged image of the microstructure of Mg-6Ag which shows a feather-like structure. (d) Enlarged image of the microstructure of Mg-10Ag, MgAg precipitates can be seen.

\section{Mechanical Properties}

The pulling direction during the tensile test is perpendicular to the growth direction of the samples. Some exemplary stress strain curves are shown in Figure 3. Furthermore, the average values and the calculated standard deviation of the yield strength $\left(\mathrm{R}_{\mathrm{p} 0.2}\right)$ and the elongation at fracture are shown. Mg shows the lowest yield strength with $\sim 150 \mathrm{MPa}$. The yield strength is increased with an increasing concentration of $\mathrm{Ag}$. $\mathrm{Mg}-10 \mathrm{Ag}$ shows the highest yield strength with $\sim 371 \mathrm{MPa}$ but also the lowest elongation at fracture with $\sim 4 \%$.

\section{Analysis of Fracture}

The fractured surfaces were examined by SEM. In Figure 4 exemplary images taken form an angle of the fractured surfaces of Mg-6 Ag (a) and an enlargement of the fractured surface (b) are shown. Mg-6 Ag was chosen because it showed the lowest corrosion rate (Jessen et al., 2019) and an increased yield strength compared to pure $\mathrm{Mg}$, but the elongation at fracture was in the same range as $\mathrm{Mg}$. The fractured surface of $\mathrm{Mg}-6 \mathrm{Ag}$ looked alike compared to $\mathrm{Mg}$ and all the $\mathrm{Mg}-\mathrm{Ag}$ alloys. The fractured surface is rough indicating a moderately ductile fracture. This goes along with the results from the tensile test in which the elongation at fracture is about 7\% for alloys up to $8 \mathrm{wt} \% \mathrm{Ag}$. Even $\mathrm{Mg}-10 \mathrm{Ag}$ showed the same fractured surface although this alloy exhibits the lowest elongation at fracture of the investigated materials with about $4 \%$.

Figure 5 shows three normalized rocking curves for $\mathrm{Mg}-6 \mathrm{Ag}$ after tensile test at different positions on the dog-bone shaped 


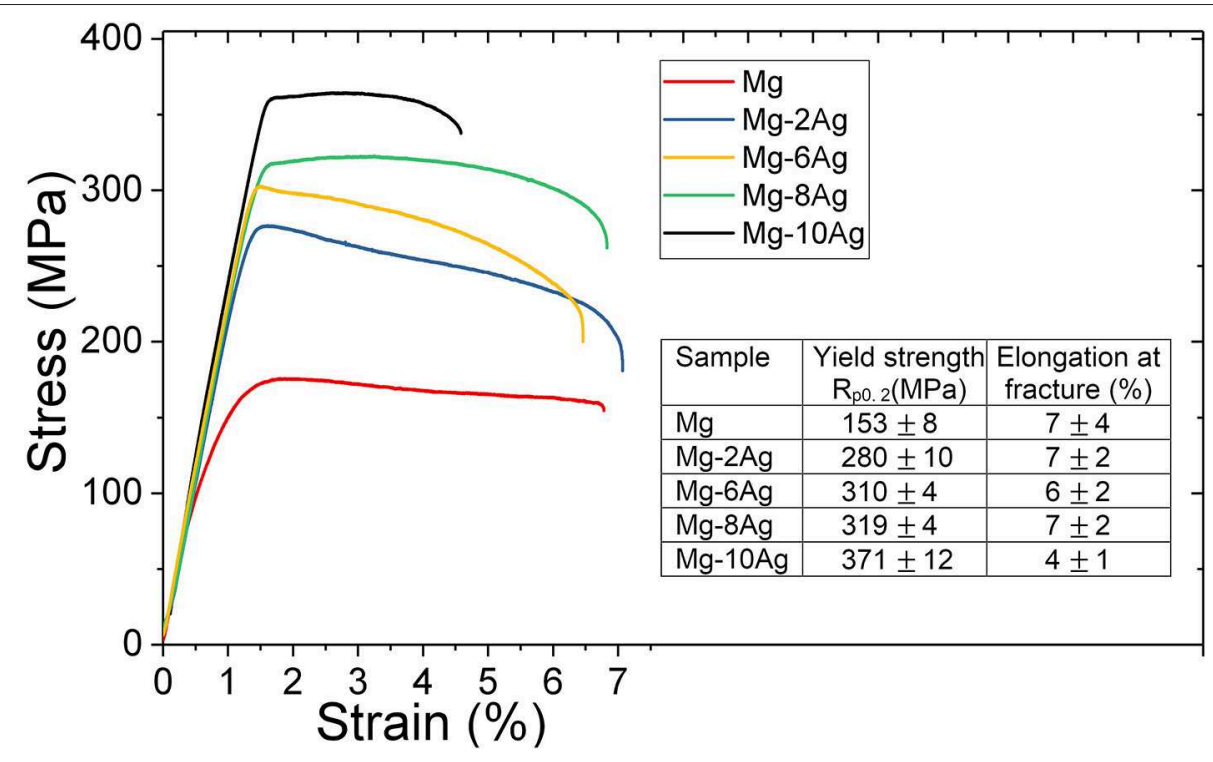

FIGURE 3 | Exemplary stress strain curves of Mg, Mg-2Ag, Mg-6Ag, Mg-8Ag, and Mg-10Ag. With increasing amount of Ag the yield strength increases. From 153 $\mathrm{MPa}$ for pure Mg to $\sim 371 \mathrm{MPa}$ for Mg-10Ag. Up to $8 \mathrm{wt} \% \mathrm{Ag}$ the elongation at break is in the same range as Mg but for Mg-10Ag the elongation at break is decreased to $\sim 4 \%$. The table shows the average values and calculated standard deviation of yield strength (MPa) and elongation at break (\%).
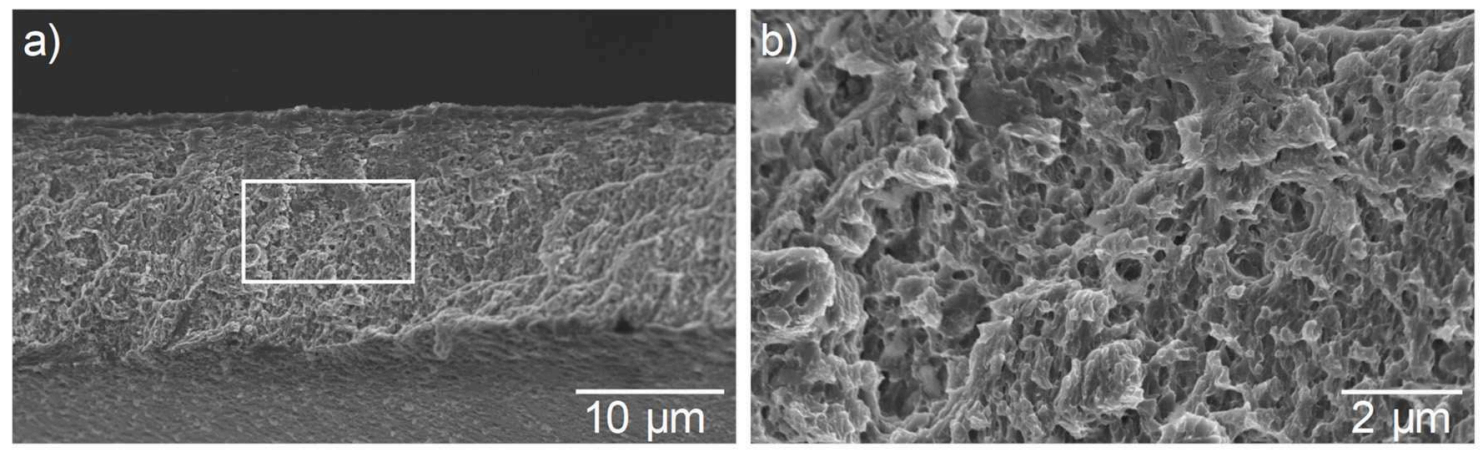

FIGURE 4 | Image taken from an angle of the fractured surface (a) Mg-6Ag, (b) Enlargement of fractured surface. The Images show a rough fractured surface, indicating a moderate ductile fracture.

sample to determine the change in full width half maximum (FWHM). The exemplary rocking curves of $\mathrm{Mg}$-6Ag were chosen, because of the promising corrosion results and that the elongation at fracture of $\sim 6 \%$. The FWHM was determined by Gaussian fit. Additionally, the standard error of the fit is given. Furthermore, a dog-bone shaped sample is shown and the different positions for the measurements. The rocking curve measured on the head of the dog-bone exhibits the smallest FWHM. There should be no deformation at the head of the dogbone. The measurement on the strut next to the head shows an increase in the FWHM. The highest FWHM is detected for the measurement on the strut next to the fracture, which is the area with the highest deformation. This curve shows also an asymmetric behavior. Furthermore, a shift of the nondeformed measurement and the deformed measurement can be seen.

\section{DISCUSSION}

Mg based alloys have a hexagonal close packed structure. These materials have less gliding systems compared to cubic metals which results in a lower deformability at room temperature (RT). The dominant deformation mechanism at temperature below $225^{\circ} \mathrm{C}$ will be slip on the basal $\{0001\}$ planes in the $<11 \overline{2} 0>$ directions. But also on the pyramidal planes $\{10 \overline{1} 1\}$ and $\{11 \overline{2} 2\}$ deformation can occur as well as the prismatic slip planes can be activated (Beck, 1939; Ion et al., 1982; Numakura and Koiwa, 1998; Kammer, 2000; Staroselsky, 2003; Schlüter et al., 2013). Twinning on the $\{10 \overline{1} 2\}$ planes in the $<\overline{1} 011>$ direction is theoretically possible but here no hints of twinning were found. Due to the preferential orientated microstructure of the sputtered films it is most likely that the deformation will occur on the pyramidal plane at RT because these slip systems 


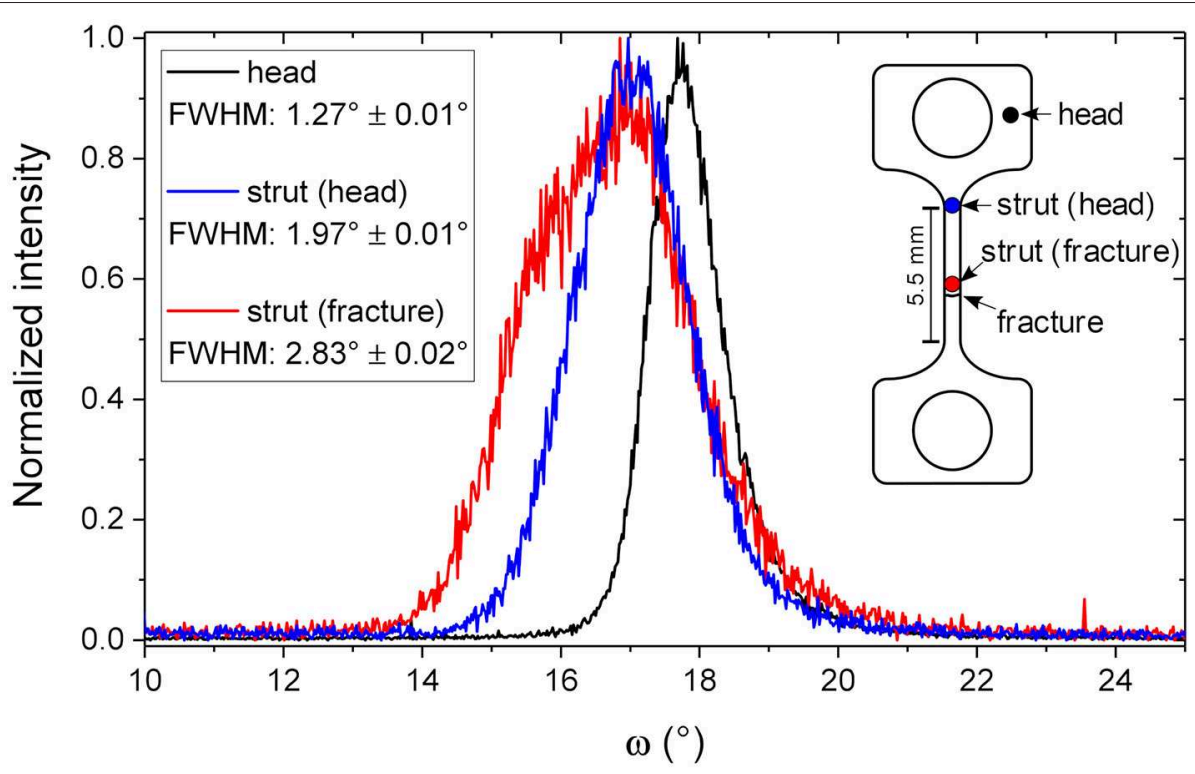

FIGURE 5 | Three different normalized rocking curves of Mg-6Ag measured at different positions on the dog-bone after tensile test are shown. Furthermore, a dog-bone shaped sample is shown and the different measurement points. Head: measurement on the head of the dog-bone; nearly non-deformed area; strut (head): measurement on the strut near the head of the dog-bone, less deformed area; strut (fracture): measurement near the fractured surface, high deformation area. A shift of the non-deformed and deformed curve can be seen. Furthermore, shows the curve of the deformed state an asymmetric behavior. The FWHM was obtained from the rocking curves by Gaussian fit furthermore the standard error of the fit is given. With increasing deformation, the FWHM is increased.

have the highest possibility to be activated due to Schmid's law. A shift of the maximum and the asymmetry of the peak during the rocking curve measurements of the (0002) plane, indicates the movement along these slip plane directions. Furthermore, the comparison of the FWHM shows that it increases from the non-deformed state at the head of the dog-bone shaped sample via a less deformed state to the high deformed state close to the fracture. This indicates that the defect density is increased at the facture. The different alloys up to $8 \mathrm{wt} \% \mathrm{Ag}$ showed a moderate ductility. The results of the tensile tests showed an elongation at fracture of $\sim 7 \%$ and the SEM images of the fractured surfaces showed a rough surface which is an indication of a moderate ductile behavior. This is also in accordance with the results of the FWHM measurements, which showed that there is a plastic deformation within the materials which leads to an increase in the FWHM. Only Mg-10Ag showed a lower value for the elongation at fracture with $\sim 4 \%$ however, it exhibits the highest yield strength.

The investigated sputtered free standing films in this study show a high mechanical strength in the tensile tests. The high strength of sputtered films results from a high defect density in the films and from small grains. Compared to $\mathrm{Mg}$ film (thickness of $20 \mu \mathrm{m}$ ) the strength of $\mathrm{Mg}-\mathrm{Ag}$ alloys is even doubled. Different hardening mechanism play a role for the different sputtered films. Due to the fabrication process of magnetron sputtering the films have a high initial defect density (Thornton, 2003). These defects in the films act as obstacles and lead to the higher strength of the sputtered films. Another effect for the strength of the materials is the grain diameter. The grain diameter of the different sputtered materials is similar and smaller than $1 \mu \mathrm{m}$ (Jessen et al., 2019). In agreement with the Hall-Petch relation the small grain diameter leads to a higher strength (Hall, 1951; Gottstein, 2004). Due to similar grain diameters of the different alloys, the increased strength is a result of the higher Ag content. The increasing strength with $\mathrm{Ag}$ content can be explained by different hardening mechanisms. In accordance with the $\mathrm{Mg}$ - $\mathrm{Ag}$ phase diagram the solubility of $\mathrm{Ag}$ in $\mathrm{Mg}$ is up to $15 \mathrm{wt} \%$ at higher temperatures $(745 \mathrm{~K}$ ) given, at RT only maximum $2 \mathrm{wt} \%$ can be dissolved (ASM International, 1992b). The strength of Mg-2Ag can be explained by solid solution hardening (Gottstein, 2004). The feather-like microstructure of the Mg-6Ag sample, shows agglomeration of $\mathrm{Ag}$ without the formation of a second intermetallic phase. This potentially leads to a higher solid solution hardening compared $\mathrm{Mg}-2 \mathrm{Ag}$. In the case of $\mathrm{Mg}-10 \mathrm{Ag}$ precipitates are formed ranging from 10 to $50 \mathrm{~nm}$ (Figure 2d). The maximum ultimate strength in these alloy system is obtained by a combination of solution hardening and additionally precipitation hardening (Gottstein, 2004).

In principle one should note that a comparison of the mechanical properties obtained by different authors might be misleading due to different sample geometries, microstructures and measurement systems. The as cast $\mathrm{Mg}-6 \mathrm{Ag}$ wires are in a similar range as the investigated thin film samples here. The wires of Mg-6 Ag had an ultimate strength of $\sim 350 \mathrm{MPa}$ and an elongation at fracture of 5\% (Maier et al., 2018). The sputtered $\mathrm{Mg}-6 \mathrm{Ag}$ samples are in the range of $310 \mathrm{MPa}$ and exhibited an elongation at fracture of $\sim 6 \%$. But the thin films show a lower corrosion rate compared to the bulk materials, which can be a result of the smaller grain size and the columnar 
microstructure of the sputtered thin films (Liu et al., 2008; Jiang et al., 2017). It is well-established that the mechanical properties can be influenced by an additional heat treatment which will result in a higher elongation at fracture but will decrease the ultimate strength. Additionally, the corrosion properties will be changed, due to larger grain diameters and possible the formation of precipitates, the corrosion rate will be increased (Ralston et al., 2010).

\section{CONCLUSION}

It was shown that magnetron sputtering is a suitable method for the fabrication of $20 \mu \mathrm{m}$ thick $\mathrm{Mg}-\mathrm{Ag}$ films which show a moderate ductile behavior. $\mathrm{Mg}$-Ag samples in the range of 2-8 wt\% Ag showed similar ductility as $\mathrm{Mg}$ with an elongation at fracture of $\sim 7 \%$. Furthermore, it was shown that it is possible to influence the yield strength with the addition of Ag. For $10 \mathrm{wt} \%$ Ag samples the ductility was decreased, but this alloy showed the highest strength of $\sim 371 \mathrm{MPa}$. For Mg-6Ag the yield strength could be increased by a factor of two from $\sim 150 \mathrm{MPa}$ of $\mathrm{Mg}$ to $\sim 310 \mathrm{MPa}$ with an elongation at fracture of $\sim 6 \%$. These results in combination with the low corrosion rate of Mg-6 Ag (Jessen et al., 2019) makes this material to a very promising candidate for future biodegradable medical implants.

\section{REFERENCES}

ASM International (1992a). ASM Handbook Volume 2: Properties and Selection: Nonferrous Alloys and Special-Purpose Materials. Materials Park, OH: ASM International.

ASM International (1992b). Volume 3-Alloy Phase Diagrams, 10th Edn. Materials Park, OH: ASM International.

ASM International (1999). ASM Specialty Handbook-Magnesium and MagnesiumAlloys. Materials Park, OH: ASM International.

Beck, A. (1939). Magnesium und Seine Legierungen. Berlin; Heidelberg: SpringerVerlag GmbH.

Gao, L., Chen, R. S., and Han, E. H. (2009a). Solid solution strengthening behaviors in binary Mg-Y single phase alloys. J. Alloys Compd. 472, 234-240. doi: 10.1016/j.jallcom.2008.04.049

Gao, L., Chen, R. S., and Han, E. H. (2009b). Effects of rare-earth elements Gd and $\mathrm{Y}$ on the solid solution strengthening of Mg alloys. J. Alloys Compd. 481, 379-384. doi: 10.1016/j.jallcom.2009.02.131

Gottstein, G. (2004). Physical Foundation of Material Science, 1st Edn. Berlin; Heidelberg: Springer-Verlag GmbH.

Haffner, D., Zamponi, C., De Miranda, R. L., and Quandt, E. (2015). Micropatterned freestanding magnetron sputtered Mg-alloy scaffolds, BioNanoMater. 16, 19-22. doi: 10.1515/bnm-2015-0007

Hall, E. O. (1951). The deformation and ageing of mild steel III Discussion of results. Proc. Phys. Soc. Sect. 64:747. doi: 10.1088/0370-1301/64/9/303

Hermawan, H. (2012). Biodegradable Metals: From Concept to Applications. Springer Science \& Business Media. doi: 10.1007/978-3-642-31170-3

Hermawan, H., Dubé, D., and Mantovani, D. (2010). Developments in metallic biodegradable stents. Acta Biomater. 6, 1693-1697. doi: 10.1016/j.actbio.2009.10.006

Hort, N., Huang, Y., Fechner, D., Störmer, M., Blawert, C., Witte, F., et al. (2010). Magnesium alloys as implant materials-Principles of property design for Mg-RE alloys. Acta Biomater. 6, 1714-1725. doi: 10.1016/j.actbio.2009. 09.010

\section{DATA AVAILABILITY STATEMENT}

The datasets generated for this study are available on request to the corresponding author.

\section{AUTHOR CONTRIBUTIONS}

The work was completed by cooperation of all authors. LJ, CZ, and EQ contributed on the concept and design of the project. LJ and CZ performed the experiments. $\mathrm{LJ}$ wrote the first draft of the manuscript. $\mathrm{CZ}$ and $\mathrm{EQ}$ revised the first draft of the manuscript. All authors read and approved the submitted version.

\section{FUNDING}

Funding by the DFG was gratefully acknowledged. This work was developed in the framework of the research training group GRK 2154 Materials for Brain.

\section{ACKNOWLEDGMENTS}

The authors thank Dr. Ulrich Schürmann from the Chair of Synthesis and Real Structure from the CAU Kiel for conducting the TEM investigations.

Ion, S. E., Humphreys, F. J., and White, S. H. (1982). Dynamic recrystallisation and the development of microstructure during the high temperature deformation of magnesium. Acta Metall. 30, 1909-1919. doi: 10.1016/0001-6160(82)90031-1

Jessen, L. K., Zamponi, C., Willumeit-Römer, R., and Quandt, E. (2019). Magnetron sputtered freestanding mgag films with ultra-low corrosion rate. Acta Biomater. doi: 10.1016/j.actbio.2019.05.060. [Epub ahead of print].

Jiang, B., Xiang, Q., Atrens, A., Song, J., and Pan, F. (2017). Influence of crystallographic texture and grain size on the corrosion behaviour of as-extruded $\mathrm{Mg}$ alloy AZ31 sheets. Corros. Sci. 126, 374-380. doi: 10.1016/j.corsci.2017.08.004

Kammer, C. (2000). Magnesium Taschenbuch. Düsseldorf: Aluminium-Verlag.

Laermer, F., and Schilp, A. (1996). Method of Anistropically Etching Silicon, US patent No. 5501893.

Lansdown, A. B. G. (2002). Silver I: its antibacterial properties and mechanism of action. J. Wound Care. 11, 125-130. doi: 10.12968/jowc.2002.11.4.26389

Li, L., Gao, J., and Wang, Y. (2004). Evaluation of cyto-toxicity and corrosion behavior of alkali-heat-treated magnesium in simulated body fluid. Surf. Coatings Technol. 185, 92-98. doi: 10.1016/j.surfcoat.2004.01.004

Liu, D., Dai, X., Wen, X., Qin, G., and Meng, X. (2015a). Crystallographic information of intermediate phases in binary $\mathrm{Mg}-\mathrm{X}(\mathrm{X}=\mathrm{Sn}, \mathrm{Y}, \mathrm{Sc}, \mathrm{Ag})$ alloys. Data Br. 4, 190-192. doi: 10.1016/j.dib.2015.05.011

Liu, D., Dai, X., Wen, X., Qin, G., and Meng, X. (2015b). Predictions on the compositions, structures, and mechanical properties of intermediate phases in binary Mg-X (X = Sn, Y, Sc, Ag) alloys. Comput. Mater. Sci. 106, 180-187. doi: 10.1016/j.commatsci.2015.04.038

Liu, M., Qiu, D., Zhao, M. C., Song, G., and Atrens, A. (2008). The effect of crystallographic orientation on the active corrosion of pure magnesium. Scr. Mater. 58, 421-424. doi: 10.1016/j.scriptamat.2007.10.027

Liu, Z., Schade, R., Luthringer, B., Hort, N., Rothe, H., Müller, S., et al. (2017). Influence of the microstructure and silver content on degradation, cytocompatibility, and antibacterial properties of magnesium-silver alloys in vitro. Oxid. Med. Cell. Longev. 2017:8091265. doi: 10.1155/2017/8091265

Mahieu, S. (2006). Biaxial alignment in sputter deposited thin films. Thin Solid Films 515, 1229-1249. doi: 10.1016/j.tsf.2006.06.027 
Maier, P., Szakács, G., Wala, M., and Hort, N. (2015). “Mechanical and corrosive properties of two magnesium wires: Mg4Gd and Mg6Ag," in Magnesium Technology (Cham: Springer), 393-398.

Maier, P., Zimmermann, F., Rinne, M., Szakács, G., Hort, N., and Vogt, C. (2018). Solid solution treatment on strength and corrosion of biodegradable $\mathrm{Mg} 6 \mathrm{Ag}$ wires, mater. Corros 69, 178-190. doi: 10.1002/maco.201709502

Mijnendonckx, K., Leys, N., Mahillon, J., Silver, S., and Van Houdt, R. (2013). Antimicrobial silver: Uses, toxicity and potential for resistance. BioMetals. 26, 609-621. doi: 10.1007/s10534-013-9645-Z

Musil, J. (2012). Hard nanocomposite coatings: thermal stability, oxidation resistance and toughness. Surf. Coat. Technol. 207, 50-65. doi: 10.1016/j.surfcoat.2012.05.073

Musil, J. (2015). Flexible hard nanocomposite coatings. RSC Adv. 5, 60482-60495. doi: 10.1039/C5RA09586G

Numakura, H., and Koiwa, M. (1998). Dislocations in metals and alloys with the hexagonal close-packed structure. Metall. Sci. Tecnol. 16, 4-19.

Ralston, K. D., Birbilis, N., and Davies, C. H. J. (2010). Revealing the relationship between grain size and corrosion rate of metals. Scr. Mater. 63, 1201-1204. doi: 10.1016/j.scriptamat.2010.08.035

Ren, Y., Zhao, H., Wang, L., Yang, B., Li, H., Sun, S., et al. (2018). Evidence of a novel intermetallic $\mathrm{Mg} 7 \mathrm{Ag} 3$ phase in $\mathrm{Mg}$-ag binary alloy system. J. Appl. Crystallogr. 51, 844-848. doi: 10.1107/S160057671800599X

Schluter, K., Reverey, J., Hort, N., Zamponi, C., and Quandt, E. (2011). Mechanical behaviour and corrosion performance of thin film magnesium WE alloys. Light Met. Technol. 690, 286-289. doi: 10.4028/www.scientific.net/MSF.690.286

Schlüter, K., Shi, Z., Zamponi, C., Cao, F., Quandt, E., and Atrens, A. (2014). Corrosion performance and mechanical properties of sputter-deposited MgY and MgGd alloys. Corros. Sci. 78, 43-54. doi: 10.1016/j.corsci.2013.08.027

Schlüter, K., Zamponi, C., Hapke, J., Hort, N., Kainer, K. U., and Quandt, E. (2013). Mechanical properties and corrosion behaviour of freestanding, precipitate-free magnesium WE43 thin films. Int. J. Mater. Res. 104, 286-292. doi: $10.3139 / 146.110860$

Song, G. (2007). Control of biodegradation of biocompatable magnesium alloys. Corros. Sci. 49, 1696-1701. doi: 10.1016/j.corsci.2007.01.001
Staiger, M. P., Pietak, A. M., Huadmai, J., and Dias, G. (2006). Magnesium and its alloys as orthopedic biomaterials: a review, Biomaterials 27, 1728-1734. doi: 10.1016/j.biomaterials.2005.10.003

Staroselsky, A. L. (2003). A constitutive model for hcp materials deforming by slip and twinning: application to magnesium alloy AZ31B. Int. J. Plast. 19, 1843-1864. doi: 10.1016/S0749-6419(03)00039-1

Thompson, C., V. (1990). Grain growth in thin films. Annu. Rev. Mater. Sci. 20, 245-268. doi: 10.1146/annurev.ms.20.080190. 001333

Thornton, J. A. (2003). High rate thick film growth. Annu. Rev. Mater. Sci. 7, 239-260. doi: 10.1146/annurev.ms.07.080177.001323

Tie, D., Feyerabend, F., Hort, N., Hoeche, D., Kainer, K. U., Willumeit, R., et al. (2014). In vitro mechanical and corrosion properties of biodegradable $\mathrm{Mg}$ - $\mathrm{Ag}$ alloys. Mater. Corros. 65, 569-576. doi: 10.1002/maco.201206903

Tie, D., Feyerabend, F., Müller, W., Schade, R., Liefeith, K., and Kainer, K. U. (2013). Antibacterial biodegradable Mg-Ag alloys. Eur. Cell Mater. 25, 284-298. doi: 10.22203/eCM.v025a20

Witte, F., Hort, N., Vogt, C., Cohen, S., Kainer, K. U., Willumeit, R., et al. (2008). Degradable biomaterials based on magnesium corrosion. Curr. Opin. Solid State Mater. Sci. 12, 63-72. doi: 10.1016/j.cossms.2009.04.001

Zheng, Y. F., Gu, X. N., and Witte, F. (2014). Biodegradable metals. Mater. Sci. Eng. R. 77, 1-34. doi: 10.1016/j.mser.2014.01.001

Conflict of Interest: The authors declare that the research was conducted in the absence of any commercial or financial relationships that could be construed as a potential conflict of interest.

Copyright (c) 2019 Jessen, Zamponi and Quandt. This is an open-access article distributed under the terms of the Creative Commons Attribution License (CC BY). The use, distribution or reproduction in other forums is permitted, provided the original author(s) and the copyright owner(s) are credited and that the original publication in this journal is cited, in accordance with accepted academic practice. No use, distribution or reproduction is permitted which does not comply with these terms. 